\title{
Overexpression of Caveolin-1 in Cancer-Associated Fibroblasts Predicts Good Outcome in Breast Cancer
}

\author{
Shan-Wei Wang ${ }^{a, b} \quad$ Kan-Lun Xu ${ }^{c} \quad$ Shu-Qin Ruan ${ }^{a} \quad$ Li-Li Zhao $^{a} \quad$ Li-Rong Chen $^{c}$ \\ ${ }^{a}$ Key Laboratory of Cancer Prevention and Intervention (China National Ministry of Education), The Second Affiliated Hospital, \\ Zhejiang University School of Medicine, Hangzhou, \\ ${ }^{b}$ Department of Pathological Anatomy, School of Basic Medicine, Xi'an Medical College, Xi'an, \\ 'Department of Pathology, The Second Affiliated Hospital, Zhejiang University School of Medicine, Hangzhou, China
}

\section{Keywords}

Breast cancer - Cancer-associated fibroblasts .

Biomarker · Gene · Prognosis

\section{Summary}

Background: The aim of this study was to investigate the expression of caveolin-1 (Cav-1) in cancer-associated fibroblasts (CAFs) and to explore its correlation with clinicopathologic parameters and prognosis. Materials and Methods: Cav- 1 expression was detected in the stroma of 143 patients with breast cancer, 10 patients with ductal carcinoma in situ (DCIS), and 10 normal breast tissue samples. Results: Overexpression of stromal Cav-1 in breast cancer was associated with histological type, low histological grade, estrogen receptor (ER) negativity, and molecular subtypes. The expression rate of stromal Cav-1 in breast cancer $(65.7 \%, 94 / 143)$ was significantly higher than that of DCIS $(0 \%, 0 / 10)$ and normal breast tissue $(0 \%, 0 / 10)(p=0.000)$. A positive correlation was found between stromal Cav-1 and ER ( $p=0.046, r s=0.218$ ). Stromal Cav-1 expression in luminal $B$ was significantly higher than in basal-like type ( $p=0.048$ ). Furthermore, stromal expression of Cav-1 was significantly correlated with the 5-year survival rate $(p=0.029)$, and it was an independent prognostic factor $(p=0.009)$. Conclusion: Cav-1 expression in CAFs was correlated with histological type, histological grade, ER status, and molecular subtypes in breast cancer. Stromal Cav-1 expression was an independent prognostic factor, and the absence or reduction of Cav-1 expression in stromal CAFs of invasive breast cancer predicts poor prognostic outcome.

\author{
Schlüsselwörter \\ Mammakarzinom - Karzinomassoziierte Fibroblasten . \\ Biomarker · Gen · Prognose
}

\section{Zusammenfassung}

Hintergrund: Ziel dieser Studie war es, die Expression von Caveolin-1 (Cav-1) in karzinomassoziierten Fibroblasten (CAFs) und ihre Korrelation mit klinisch-pathologischen Parametern und Prognose zu untersuchen. Material und Methoden: Die Cav-1-Expression wurde im Stroma von 143 Mammakarzinompatientinnen, 10 Patientinnen mit duktalem Carcinoma in situ (DCIS) und 10 normalen Brustgewebeproben bestimmt. Ergebnisse: Überexpression von Cav-1 im Stroma von Mammakarzinomen war mit dem histologischen Typ, einem niedrigen histologischen Grad, Östrogenrezeptor (ER)Negativität und molekularem Subtyp assoziiert. Die Expressionsrate von stromalem Cav-1 beim Mammakarzinom $(65,7 \%$, 94/143) war signifikant höher als beim DCIS $(0 \%, 0 / 10)$ und im normalen Brustgewebe $10 \%$, $0 / 10)(p=0,000)$. Zwischen stromalem Cav-1 und ER bestand eine positive Korrelation ( $p=0,046, r s=0,218$ ). Die Expression von stromalem Cav-1 im Luminal-BSubtyp war signifikant höher als im Basal-like-Subtyp $(p=0,048)$. Desweiteren war die stromale Expression von Cav-1 signifikant mit dem 5-Jahresüberleben korreliert $(p=0,029)$ und wurde als ein unabhängiger Prognosefaktor identifiziert ( $p=0,009$ ). Schlussfolgerung: Die Cav-1-Expression in CAFs beim Mammakarzinom war mit dem histologischen Typ und Grad, dem ER-Status sowie dem molekularen Subtyp korreliert. Die stromale Cav-1-Expression war ein unabhängiger Prognosefaktor, und fehlende bzw. reduzierte Cav-1-Expression in stromalen CAFs beim invasiven Mammakarzinom ist indikativ für ein schlechtes Outcome.

\section{KARGER \\ Fax +497614520714 \\ Information@Karger.de}

www.karger.com (c) 2012 S. Karger GmbH, Freiburg

$1661-3791 / 12 / 0076-0477 \$ 38.00 / 0$

Accessible online at:

www.karger.com/brc
Li-Rong Chen, MD

Department of Pathology

The Second Affiliated Hospita

Zhejiang University School of Medicine

Hangzhou, 310009, Zhejiang Province, China

Chenlr1999@163.com 


\section{Introduction}

Carcinoma cells grow in a compound tumor microenvironment composed of fibroblasts, pericytes, endothelial and inflammatory cells, extracellular matrix, and secreted diffusible growth factors/cytokines [1, 2]. Caveolins are the principal protein component of caveolae which are located at the cell surface of the above cell types [3]. Under normal physiological conditions, the stroma serves as an important barrier to malignant transformation. However, its role changes during neoplastic transformation when it facilitates cancer cell invasion and progression instead [4]. Recently, it was indicated that fibroblasts isolated from tumor stroma can promote tumor growth compared with normal stroma. This population of tissue fibroblasts has been termed 'cancer-associated fibroblasts' (CAFs) and is characterized by a hyperproliferative phenotype. These cells secrete increased amounts of growth factors, extracellular matrix components, and matrix metalloproteinases [5]. CAFs also show an ability to prevent cancer cell apoptosis, induce cancer cell proliferation, and stimulate tumor angiogenesis [6]. Some studies of breast carcinomas showed that CAFs mixed with epithelial carcinoma cells are more proficient than normal fibroblasts at enhancing tumor growth, and give rise to highly vascularized tumors in vitro [7].

To date, the mechanisms that govern the conversion of benign mammary stromal fibroblasts to CAFs are poorly understood, and their relationship with disease outcome has not been addressed. Down-regulation of caveolin-1 (Cav-1) is one of the mechanisms implicated in the oncogenic transformation of fibroblasts. Cav-1 plays a major role in tumorigenesis through its various functions such as lipid transport, membrane trafficking, gene regulation, and signal transduction. Using primary cell cultures established from surgically excised breast tumors, researchers recently found that Cav-1 is downregulated in human breast CAFs when compared with matching normal fibroblasts isolated from the same patient [8]. In addition, orthotopic transplantation of Cav-1+/+ tumor tissue into the mammary stroma of Cav-1-/- null mice results in up to a 2-fold increase in tumor mass, functionally demonstrating that the mammary stroma of Cav-1-/- mice behaves as a tumor promoter [9]. However, there is no study specifically addressing the clinical significance of stromal Cav-1 expression in CAFs of invasive breast cancer in vivo. The aim of this study was to evaluate the in vivo stromal Cav-1 expression in CAFs in a large series of invasive breast carcinomas, and to examine the association between stromal Cav-1 expression, clinicopathologic variables, and patient outcome. In recent studies, it was shown that Cav-1 was expressed in many stromal components of the tumor microenvironment including the extracellular matrix, as well as in various cell types including fibroblasts, vascular endothelial cells, adipocytes, immune cells, and inflammatory cells. To clarify the relationship between Cav-1 expression in CAFs and breast cancer progres- sion or suppression, we examined tissue sections specifically for Cav-1 expression in stromal CAFs. CAFs were identified with $\alpha$-SMA as a marker to evaluated the Cav- 1 expression level. Our findings indicate that stromal Cav-1 has a potential role as a new CAFs marker for predicting outcome of breast cancer progression as well as being a possible therapeutic target.

\section{Materials and Methods}

\section{Patients and Tissue Samples}

Breast cancer tissue specimens were collected from 143 patients (median age 52 years, range 30-84 years) of the Second Affiliated Hospital of Zhejiang University School of Medicine between January 2000 and January 2006. All tissues were formalin-fixed, paraffin-embedded, and clinically and histopathologically diagnosed at the Departments of Breast Surgery and Pathology. All patients had follow-up records for over 5 years. The follow-up deadline was December 2010. The survival time was counted from the date of surgery to the follow-up deadline or date of death which was mostly caused by carcinoma recurrence or metastasis. According to the WHO histologic classification of breast carcinoma formulated in 2002, there were105 cases of invasive ductal carcinoma (IDC), 19 cases of invasive lobular carcinoma (ILC), 19 cases of mixed IDC and ILC, 10 cases of ductal carcinoma in situ (DCIS), and 10 normal breast tissue samples. Patients who had received irradiation and/or chemotherapy before surgery were excluded. Case follow-up data were obtained from the Cancer Institute of Zhejiang University School of Medicine. The median age of the IDC patients was 52 years (range 30-84 years). The median tumor diameter was $25 \mathrm{~mm}$ (range 5-70 mm). In accordance with the TNM staging system, 22 cases were stage I, 71 cases were stage II, and 50 cases were stage III. All invasive carcinomas were graded according to the method described by Elston and Ellis [10]: 29 cases grade 1,65 cases grade 2 , and 49 cases grade 3 . According to standard breast cancer molecular subtypes, 35 cases were luminal A (estrogen receptor-positive $(\mathrm{ER}+)$ and/or progesterone receptor-positive $(\mathrm{PR}+)$, human epidermal growth factor receptor 2-negative (HER2-), ki-67 $<13.25 \%), 31$ cases were luminal B (ER+ and/or PR+, HER2+), 36 cases were of HER2 overexpression type (ER- and PR-, HER2 +), and 9 cases were basal-like (ER- and PR-, HER2-, CK5/6+). The median follow-up time for all survivors was 4.9 years ( $>30$ days to 18.5 years).

\section{Immunohistochemistry}

Cav-1 expression in the tumor stroma was assessed by using a standard EnVision TM immunoperoxidase method (EnVision reagent (HRP/Rabbit) and DAB kit purchased from Dako, Glostrup, Denmark) with rabbit polyclonal anti-caveolin-1 IgG dilution 1:3,000 (ab18199; Abcam Biotechnology, Cambridge, UK), and $\alpha$-SMA dilution 1:2,000 (Epitomics Inc., Burlingame, CA, USA). For negative control, samples were processed as above but treated with phosphate-buffered saline instead of primary antibody. Colon cancer tissue served as positive control. Cav-1 expression was then evaluated in a semiquantitative manner. Only membranous with or without cytoplasmic staining was considered specific, with $\alpha$-SMApositive stromal cells being CAFs. If stromal cells showed no $\alpha$-SMA expression, Cav-1 was not evaluated. Staining was scored semiquantitatively as negative ( 0 ; no staining or staining in less than $10 \%$ of stromal cells), weak (1; either diffuse weak staining or strong staining in less than $40 \%$ of stromal cells), or strong (2; strong staining of $40 \%$ or more of the stromal cells).

\section{Fluorescence In Situ Hybridization}

To assess the HER2 gene copy number, fluorescence in situ hybridization (FISH) probes were provided by GP Medical Technologies (Beijing, 
China), with the HER2 probe labeled in red (rhodamine) and the chromosome 17 centromere-specific probe (CSP17) in green (fluorescein isothiocyanate). Probes were premixed and predenatured in hybridization buffer for ease of use. Nuclei were counterstained with intercalating fluorescent counterstain 4'-6'-diamidino-2'-phenylindole (DAPI). The HER2 amplification ratio was calculated as: HER2 total signal count/chromosome 17 total signal count. Presence of HER2 amplification was defined as an HER2 amplification ratio of greater than 2.2.

\section{Statistical Analysis}

Statistical analysis of the obtained data was performed using SPSS software, version 16.0 (SPSS Inc., Chicago, IL, USA). Associations between the presence of stromal Cav-1 and other factors, including patient age, tumor grade, tumor size, lymph node status, histological subtype, ER, PR, HER2, and molecular subtypes were evaluated using the Pearson's chisquared test. The Kaplan-Meier method was used to estimate overall survival, and differences in outcome for each variable were compared with the log-rank test. Multivariate analysis of factors affecting survival was performed using a Cox proportional hazard model. All statistical tests were two-sided, and $\mathrm{p}<0.05$ was considered to be statistically significant.

\section{Results}

\section{Caveolin-1 Expression}

Cav-1 in normal breast tissue was determined by immunostaining of tissue samples from 10 healthy individuals using a rabbit polyclonal antibody. Cav-1 immunoreactivity was observed in stromal fibroblasts and in myoepithelial cells underlying the luminal epithelial cells. Adipocytes and vascular endothelial cells were also positive for Cav-1. However, no evidence of Cav-1 expression was found in luminal epithelial cells. Consistent with our findings, a number of other reports describe the specific localization of Cav-1 to breast myoepithelial and stromal cells, but not luminal epithelial cells [11]. When Cav-1 expression was determined in 143 cases of invasive breast can- cer, $45(31.5 \%)$ showed weak, $50(35.0 \%)$ moderate, and 48 $(33.6 \%)$ strong staining. 10 cases of DCIS and interstitial cells showed no Cav-1 expression; Cav-1 in the interstitium was mixed with varying amounts of irregular banded expression of interstitial infiltrating ductal carcinoma was negative in cases of Cav-1 show the number of CAFs little or large hyperplastic collagen associated with some regions of the low differentiation of breast cancer is more common. In ILC stroma, Cav-1 expression was low with only 9 positive cases. Basal-like breast cancer cells show weak Cav-1 expression (fig. 1 A-F).

\section{Correlation Studies}

When comparing Cav- 1 stromal and $\alpha$-SMA expression and correlation with the 2-sample rank sum test, the same levels were found in 139 cases, and Cav-1 expression was higher than $\alpha$-SMA in 17 cases and lower in 7 cases; $Z$ test statistics were $0.449, p=0.653$. There was no significant difference between the 2 groups confirming that Cav- 1 is expressed at similar levels as $\alpha$-SMA. Cav- 1 expression is located in the stroma of breast cancer CAFs. 10 cases of normal breast DCIS and 10 cases of interstitial fibroblasts showed no $\alpha$-SMA expression and Cav-1 showed very little expression (positive cells $<5 \%$, so determined to be negative). The relationship between standard prognostic factors and other molecular markers with Cav-1 expression in the CAFs is shown in table 1. Cav-1 stromal staining was associated with histological type, histological grade, ER+, and molecular subtype. In IDC and mixed carcinoma, the positive rate of Cav-1 within the stroma was significantly higher than in ILC (both $\mathrm{p}=0.000$ ). The positive rate of the ER+ group of mesenchymal Cav-1 was at $74.2 \%$ higher than that of the ER-group $(52.8 \%)$; the difference was statistically significant $(\mathrm{p}=0.046)$. Stromal expression of Cav-1 was negatively correlated
Fig. 1. Stromal caveolin-1 (Cav-1) expression in human breast cancers and normal breast tissue. A The mammary intralobular stroma, vasculature, and myoepithelial cells are normally Cav-1-positive. B Cav-1 expression in the stroma of ductal carcinoma in situ; myoepithelial cells are Cav-1-positive. C Cav-1 expression in the stroma of invasive ductal carcinoma. D Absence of Cav-1 in neoplastic stroma. E Cav-1 expression in the stroma of invasive lobular carcinomas. F Weak expression of Cav-1 in the tumor epithelium of the basal-like subtype (EnVision, $\times 100$ ).
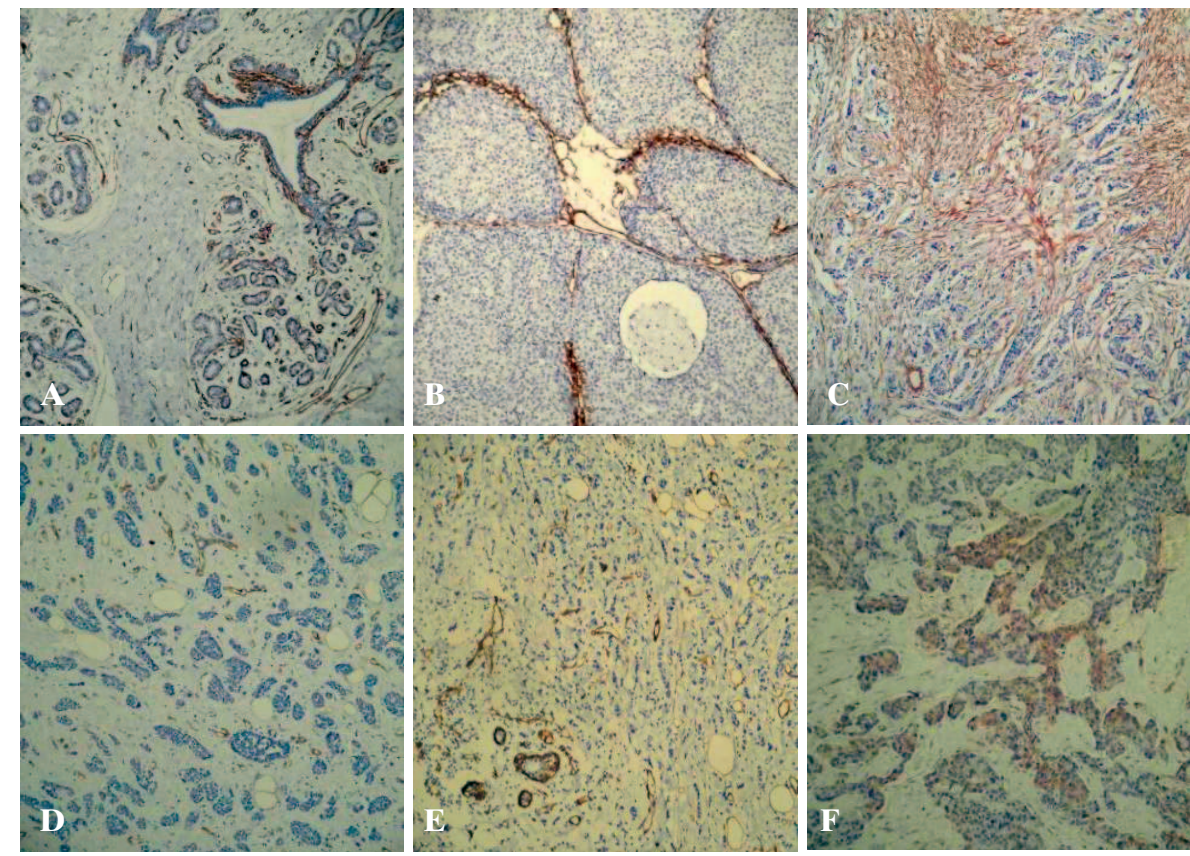
Table 1. Correlation between clinicopathologic factors and specific protein markers with caveolin-1 expression in the stroma of 143 breast cancers, and univariate survival analysis

\begin{tabular}{|c|c|c|c|c|c|c|c|c|c|}
\hline \multirow{2}{*}{$\begin{array}{l}\text { Clinicopathologic } \\
\text { features }\end{array}$} & \multirow[t]{2}{*}{ Cases, n (\%) } & \multicolumn{5}{|c|}{ Stromal Cav-1 expression } & \multirow{2}{*}{$\begin{array}{l}\text { Estimated 5-year } \\
\text { survival, n (\%) }\end{array}$} & \multirow{2}{*}{$\begin{array}{l}\text { Log-rank } \\
X^{2}\end{array}$} & \multirow[t]{2}{*}{$\mathrm{p}$ value } \\
\hline & & $0(n=45)$ & $1+(n=50)$ & $2+(n=48)$ & $\mathrm{r}_{\mathrm{s}}$ value & $\mathrm{p}$ value & & & \\
\hline T stage & & & & & -0.176 & 0.188 & & 4.070 & 0.130 \\
\hline Total & 143 & & & & & & & & \\
\hline $\mathrm{T} 1(0-20 \mathrm{~mm})$ & $52(36.4)$ & 11 & 20 & 21 & & & $52(56.6)$ & & \\
\hline $\mathrm{T} 2(21-50 \mathrm{~mm})$ & $80(55.9)$ & 28 & 28 & 24 & & & $80(56.1)$ & & \\
\hline $\mathrm{T} 3(>50 \mathrm{~mm})$ & $11(7.7)$ & 6 & 2 & 3 & & & $11(30.0)$ & & \\
\hline Axillary node status & & & & & -0.025 & 0.723 & & 8.194 & 0.042 \\
\hline Total & 143 & & & & & & & & \\
\hline N0 (0) & $59(41.3)$ & 19 & 18 & 22 & & & $59(67.8)$ & & \\
\hline N1 (1-3) & $38(26.6)$ & 11 & 14 & 13 & & & $38(52.6)$ & & \\
\hline N2 (4-9) & $19(13.3)$ & 7 & 9 & 3 & & & $19(42.1)$ & & \\
\hline $\mathrm{N} 3(\geq 10)$ & $27(18.9)$ & 8 & 9 & 10 & & & $27(40.7)$ & & \\
\hline TNM stage & & & & & -0.147 & 0.190 & & 7.204 & 0.027 \\
\hline Total & 143 & & & & & & & & \\
\hline I & $22(15.4)$ & 3 & 7 & 12 & & & $22(63.6)$ & & \\
\hline II & $71(49.6)$ & 25 & 25 & 21 & & & $71(62.0)$ & & \\
\hline III & $50(35.0)$ & 17 & 18 & 15 & & & $50(42.0)$ & & \\
\hline Age, years & & & & & 0.075 & 0,593 & & 13.388 & 0.000 \\
\hline Total & 143 & & & & & & & & \\
\hline$\leq 52$ & $61(42.7)$ & 22 & 20 & 19 & & & $61(72.1)$ & & \\
\hline$>52$ & $82(57.1)$ & 23 & 30 & 29 & & & $82(42.7)$ & & \\
\hline Tumor grade & & & & & -0.052 & 0.008 & & 7.687 & 0.021 \\
\hline Total & 143 & & & & & & & & \\
\hline 1 & $29(20.3)$ & 12 & 7 & 10 & & & $29(62.1)$ & & \\
\hline 2 & $65(45.5)$ & 19 & 17 & 29 & & & $65(59.6)$ & & \\
\hline 3 & $49(34.3)$ & 14 & 26 & 9 & & & $49(38.8)$ & & \\
\hline ER status & & & & & 0.218 & 0.046 & & 0.019 & 0.890 \\
\hline Total & 119 & & & & & & & & \\
\hline Negative & $53(44.5)$ & 25 & 16 & 12 & & & 53 (57.9) & & \\
\hline Positive & $66(55.5)$ & 17 & 25 & 24 & & & $66(58.0)$ & & \\
\hline PR status & & & & & 0.178 & 0.099 & & 0.871 & 0.351 \\
\hline Total & 118 & & & & & & & & \\
\hline Negative & $61(51.7)$ & 26 & 21 & 14 & & & $61(54.7)$ & & \\
\hline Positive & $57(48.3)$ & 15 & 20 & 22 & & & $57(63.8)$ & & \\
\hline HER2 status & & & & & 0.164 & 0.075 & & 0.001 & 0.972 \\
\hline Total & 117 & & & & & & & & \\
\hline Negative & 79 (67.5) & 26 & 26 & 27 & & & $79(60.8)$ & & \\
\hline Positive & $38(32.5)$ & 5 & 17 & 16 & & & $38(60.5)$ & & \\
\hline Molecular subtypes & & & & & -0.224 & 0.028 & & & \\
\hline Total & 111 & & & & & & & & \\
\hline Luminal A & $35(31.5)$ & 10 & 13 & 12 & & & $35(68.9$ & 7.569 & 0.056 \\
\hline Luminal B & $31(27.9)$ & 8 & 11 & 12 & & & $31(63.2)$ & & \\
\hline HER2+ type & $36(32.4)$ & 12 & 14 & 10 & & & $36(53.1)$ & & \\
\hline Basal-like type & $9(8.1)$ & 8 & 1 & 0 & & & $9(33.3)$ & & \\
\hline P53 status & & & & & 0.098 & 0.247 & & 0.001 & 0.972 \\
\hline Total & 112 & & & & & & & & \\
\hline Negative & $66(58.9)$ & 23 & 25 & 18 & & & $66(65.2)$ & & \\
\hline Positive & $46(41.1)$ & 15 & 12 & 19 & & & $46(53.2)$ & & \\
\hline Histology type & & & & & 0.216 & 0.000 & & & \\
\hline Total & 163 & & & & & & & & \\
\hline Normal tissue & $10(6.1)$ & 10 & 0 & 0 & & & & & \\
\hline DCIS & $10(6.1)$ & 10 & 0 & 0 & & & & 7.082 & 0.029 \\
\hline IDC & $105(64.4$ & 35 & 31 & 39 & & & $45(46.7)$ & & \\
\hline Mixed (IDC+ILC) & $19(11.7)$ & 4 & 10 & 5 & & & $50(48.0)$ & & \\
\hline ILC & $19(11.7)$ & 10 & 9 & 0 & & & $48(68.0)$ & & \\
\hline
\end{tabular}

$\mathrm{ER}=$ Estrogen receptor; $\mathrm{PR}=$ progesterone receptor; HER2 = human epidermal growth factor receptor 2; DCIS = ductal carcinoma in situ; IDC = invasive ductal carcinoma; ILC = invasive lobular carcinoma.

with histological grade: the higher the histological grade, the lower stromal expression of Cav-1 (Spearman correlation coefficient $r=-0.052)$. The difference was statistically significant $(\mathrm{p}=0.008)$. Cav-1-positive rates among the molecular subtypes were: luminal A 71.4\% (25/35), luminal B $74.2 \%$ (23/31), HER2+ 66.7\% (24/36), and basal-like type $11.1 \%$ (1/9), with the luminal B Cav-1-positive rate being significantly higher than that of the basal-like subtype $(\mathrm{p}=0.048)$.

\section{Survival Analysis}

Kaplan-Meier univariate survival analysis showed that factors related to a relatively poor prognosis are age $\geq 52$ years, a large number of involved lymph nodes, late TNM stage, high histological grade, and low mesenchymal Cav-1 expression levels. Multivariate statistical analyses attributed improved 5-year survival rates to elevated stromal Cav-1, independent of other established prognostic factors $(p=0.009)$. Over- 
expression of Cav-1 in CAFs in the primary tumor microenvironment is associated with improved outcome in breast cancer (fig. 2). Prognostic factors in the stratified survival analysis for invasive ductal carcinoma were TNM stage I, $\mathrm{ER}+$, lymph node metastasis N1 (number of metastatic lymph nodes 1-3); 5-year overall survival was significantly lower in the case of low or absent Cav-1 expression in stromal breast cancer CAFs than with high expression (figs. 3-6).

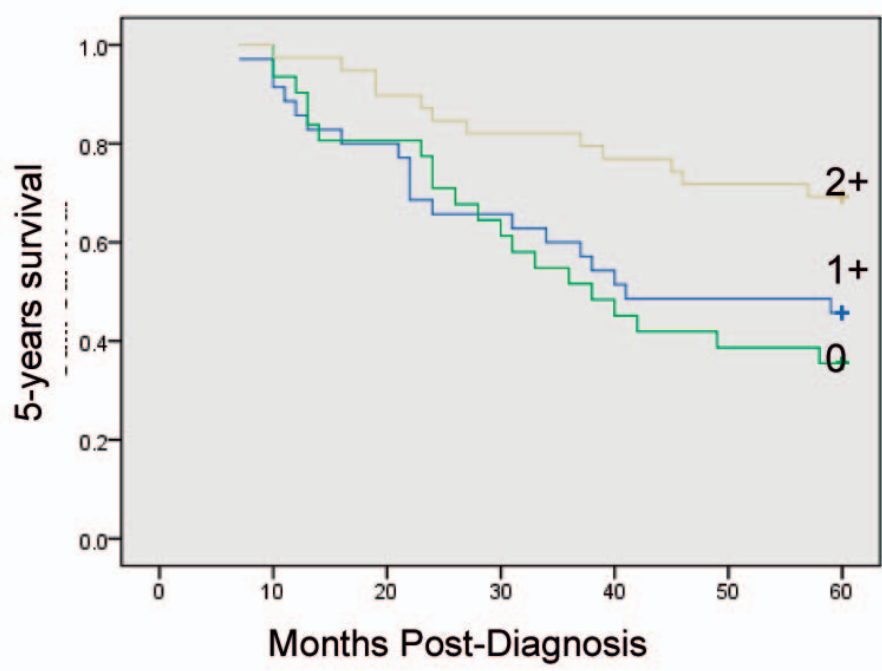

Fig. 3. Kaplan-Meier curves of 5-years survival in 105 invasive ductal carcinoma (IDC) patients. Note that a low level of stromal Cav-1 immunostaining also predicts poor clinical outcome in IDC patients $(\mathrm{p}=7.97$; $\times 10^{-3}, \log$-rank test).

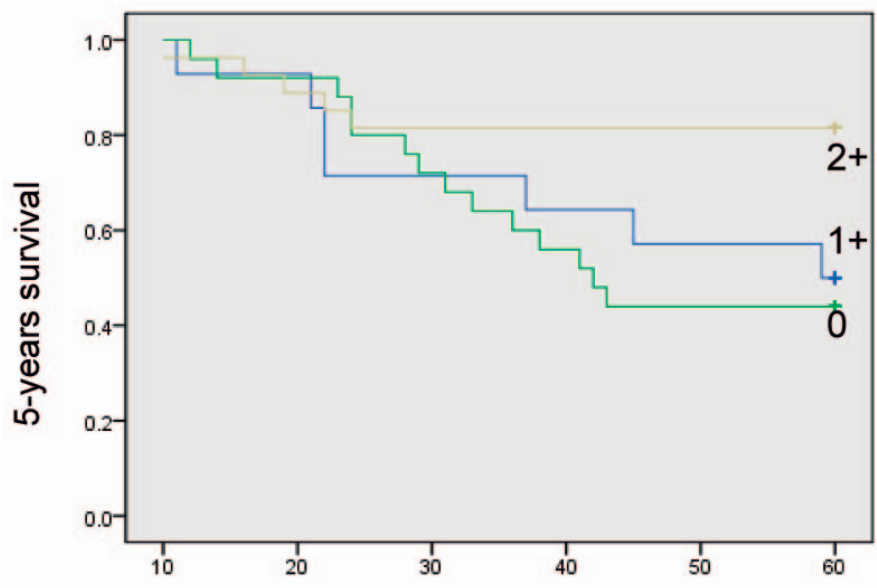

\section{Months Post-Diagnosis}

Fig. 5. Kaplan-Meier curves of 5-years survival in 66 estrogen receptorpositive patients.

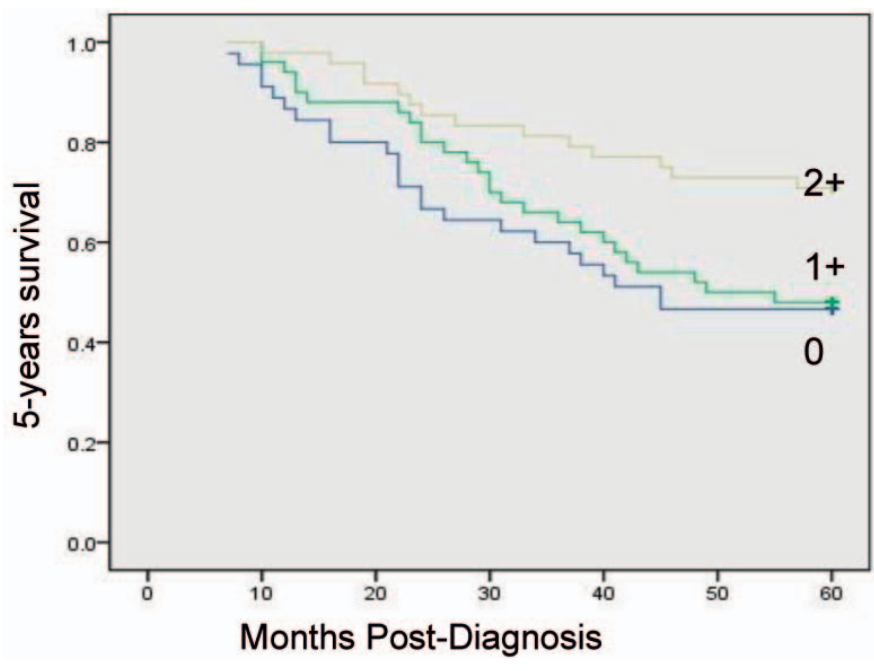

Fig. 2. Kaplan-Meier curves of 5-year survival in 143 breast cancer patients.

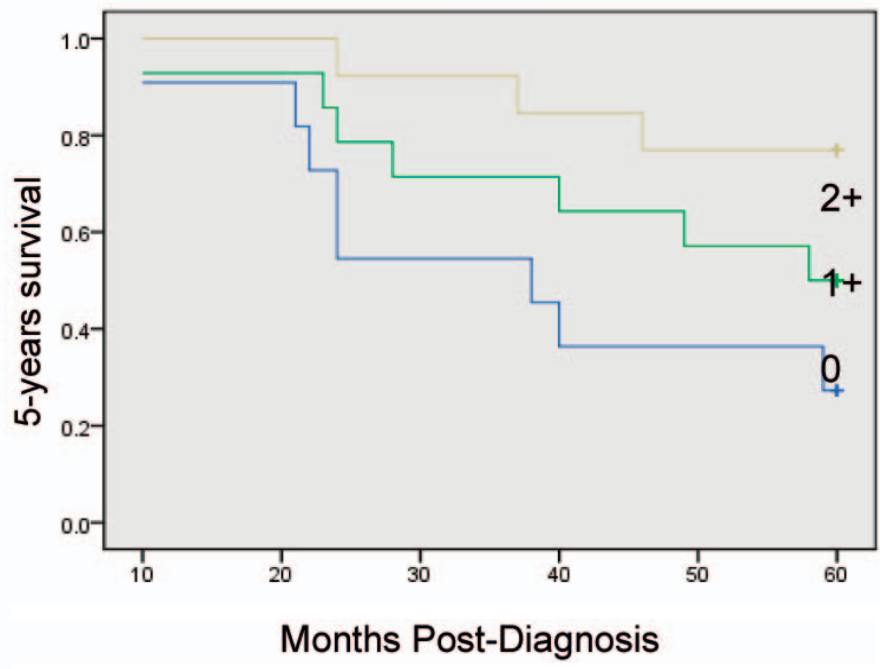

Fig. 4. Kaplan-Meier curves of 5-years survival in 38 patients with N1 lymph node status.

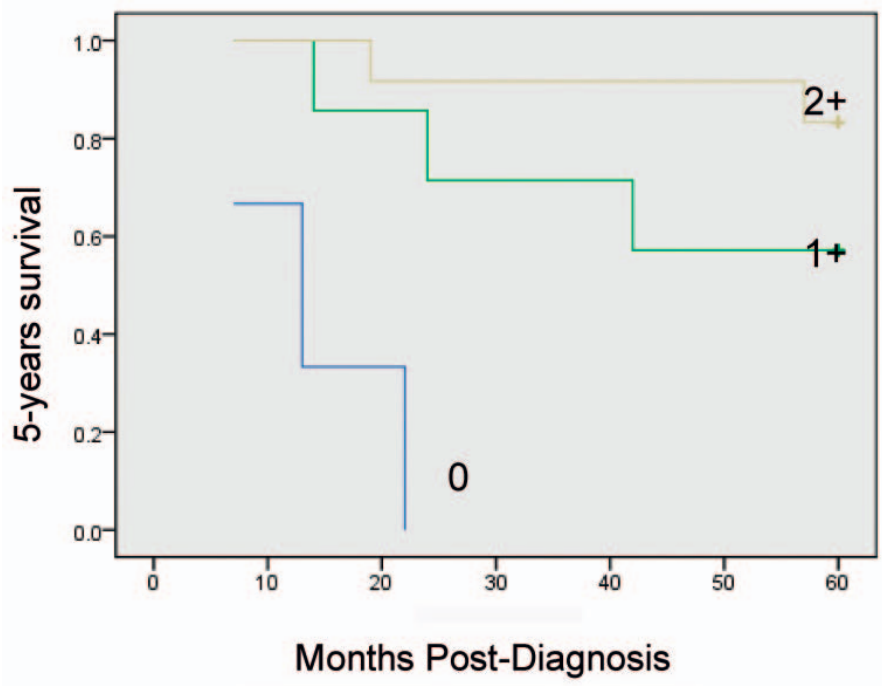

Fig. 6. Kaplan-Meier curves of 5-years survival in 22 TNM stage I patients. 


\section{Discussion}

In this study, we evaluated the expression of Cav-1 in the CAFs of invasive breast carcinomas and demonstrated that low Cav-1 expression is a strong predictor of tumor recurrence and dramatically lower progression-free survival. In vitro, some researchers used primary cell cultures established from surgically excised breast tumors, and demonstrated that Cav-1 is down-regulated in human breast CAFs when compared with matching normal fibroblasts isolated from the same patient [11]. Recently, a study confirmed that no association existed between Cav-1 expression in the epithelial compartment and clinical outcome. However, high levels of Cav-1 in the stromal tissue surrounding the tumor, rather than within tumor cells, were strongly associated with reduced metastasis and improved survival. Although stromal Cav-1 expression has been extensively studied in breast carcinomas, only few studies exist on the expression and significance of Cav-1 in the stroma of invasive breast carcinomas in vivo [12, 13]. Another study showed that absence of stromal Cav-1 was associated with early disease recurrence, advanced tumor stage, and lymph node metastasis, resulting in a 3.6-fold reduction in progression-free survival. However, to date, there is no study to confirm stromal Cav-1 expression in CAFs in vivo and a role of Cav-1 as a new marker instead of $\alpha$-SMA. The studies presented here show that $\alpha$-SMA is a specific marker for CAFs, but normal fibroblasts were negative in normal breast tissue. There was no significant difference between stromal expression of Cav-1 and $\alpha$-SMA ( $p=0.653$ ) confirming that Cav- 1 expression levels are similar to $\alpha$-SMA expression levels, and Cav-1 is also exactly located in the stroma of breast cancer CAFs.

Our results presented here show that the presence of Cav1-positive CAFs in the primary tumor microenvironment is associated with improved outcome in breast cancer. Cav-1 expression in tumor-associated fibroblasts was related to lower tumor grade and improved staging at diagnosis. Consistent with this, 5-year survival rates were significantly better in patients with Cav-1-positive CAFs. Multivariate statistical analyses attributed improved 5-year survival rates to elevated stromal Cav-1, independent of other established prognostic factors. These findings suggest that expression of Cav-1 in CAFs may be a new prognostic factor for long-term breast cancer survival.

In sporadic carcinomas, a strong association was found between Cav-1 expression and a basal-like phenotype, since $52 \%$ of tumors that expressed Cav- 1 had this phenotype [14]. We found that $9 / 9$ cases were of the basal-like subtype, close to a report that the Cav-1-positive rate in the basal-like subtype was $89.7 \%$ (35/39) [14]. In the latter cohort, Cav-1 expression was significantly associated with shorter disease-free and overall survival on univariate analysis in basal-like breast cancer [15]. Cav-1 expression in CAFs was associated with the histological type of breast cancer, with ILC showing significantly lower expression than IDC and mixed carcinoma, and the differences were statistically significant $(\mathrm{p}=0.000)$. Although Perrone [16] reported that $42 \%$ of ILC expressed Cav1, we found that Cav-1 was not expressed in 19 cases of ILC. Stromal Cav-1 was negative in 10 patients, with the other 9 cases being $1+$. However, the different results may be related to the use of different antibodies. There are still no study data indicating that stromal Cav-1 expression in ILC and IDC is significantly different, which may be due to fewer ILC cases. We collected only 19 cases, and would require more samples for larger sample comparison.

Since ER, PR, and HER2 expression have long served as important epithelial biomarkers for stratifying breast cancer patients into different diagnostic and therapeutic groups, we also assessed the status of stromal Cav-1 in these different patient groups within our cohort. Strikingly, we observed that overexpression of stromal Cav-1 effectively predicts good clinical outcome in the ER+ groups. Regarding the molecular subtypes, Cav-1 expression in the luminal B subtype was significantly higher than in the basal-like subtype. Based on the stromal Cav-1 expression in CAFs being divided into 3 categories $-0,1+$, and $2+-$ breast cancer patients can be stratified into 3 risk groups: high, moderate, and low risk. Low or absent expression in CAFs of breast cancer patients indicates a poor prognosis. We have excluded confounding factors for survival time, with the prognostic factors of stratified survival analysis in invasive ductal carcinoma being TNM stage I, $\mathrm{ER}+$, and lymph node status N1.

The 5-year survival rate of breast cancer patients was significantly lower with low Cav-1 expression than with high expression, which is in agreement with the results of Witkiewicz et al. [12]. Thus, the status of the tumor stroma may be a primary determinant of disease recurrence and poor clinical outcome in breast cancer patients. It suggests that we should be more actively targeting the tumor stroma in our therapeutic interventions.

Recently, Witkiewicz et al. [17] observed that the loss of stromal Cav-1 expression also has a predictive value for the clinical outcome in DCIS patients, regarding progression to invasive breast cancer. While the mechanisms that regulate Cav-1 production in tumor-associated stromal tissue remain unclear, it is possible that tumor cell signaling is involved in this process. Loss of Cav-1 in stromal cells may be regulated by signals originating from transformed epithelial cells to enable tumor cells to escape the growth-suppressing properties of the stroma. This may promote growth, migration, or invasion of the epithelial tumor cells. Methylation silencing may explain the loss of Cav-1 expression in stromal tissue [18] and is the subject of ongoing studies, as is the nature of the paracrine signaling between stromal and tumor cells that occurs in the presence of Cav-1. In addition to its value at first diagnosis, CAFs Cav-1 expression may be an effective prognostic 
factor, but this needs more prospective validation. In the future, prospective clinical trials will be essential to confirm the prognostic power of CAFs Cav-1 in breast cancer.

\section{Disclosure Statement}

The authors declare no conflict of interest.

\section{Acknowledgement}

We thank the Institute of Medical Oncology, and Zhejiang University lecturer Zhou Lun for providing support and assistance.

\section{References}

1 Bhowmick NA, Neilson EG, Moses HL: Stroma fibroblasts in cancer initiation and progression. Nature 2004;432:332-337.

$\checkmark 2$ Mueller MM, Fusenig NE: Friends or foes - bipolar effects of the tumour stroma in cancer. Nat Rev Cancer 2004;4:839-849.

3 Hnasko R, Lisanti MP: The biology of caveolae: lessons from caveolin knockout mice and implications for human disease, Mol Interv 2003;3:445464.

4 Kim JB, Stein R, O'Hare MJ: Tumour-stromal interactions in breast cancer: the role of stroma in tumourigenesis. Tumour Biol 2005;26:173-185.

5 Kalluri R, Zeisberg M: Fibroblasts in cancer. Nat Rev Cancer 2006;6:392-401.

6 Serini G, Gabbiani G: Mechanisms of myofibroblast activity and phenotypic modulation. Exp Cell Res 1999;250:273-283.

7 Orimo A, Gupta PB, Sgroi DC, ArenzanaSeisdedos F, Delaunay T, Naeem R, Carey VJ, Richardson AL, Weinberg RA: Stromal fibroblasts present in invasive human breast carcinomas promote tumor growth and angiogenesis through elevated SDF-1/CXCL12 secretion. Cell 2005; 121:335-348.

8 Mercier I, Casimiro MC, Wang C, Rosenberg AL, Quong J, Minkeu A, Allen KG, Danilo C, Sotgia F, Bonuccelli G, Jasmin JF, Xu H, Bosco E, Aronow B, Witkiewicz A, Pestell RG, Knudsen ES, Lisanti MP: Human breast cancer-associated fibroblasts (CAFs) show caveolin-1 downregulation and $\mathrm{RB}$ tumor suppressor functional inactivation: implications for the response to hormonal therapy. Cancer Biol Ther 2008;7:1212-1225.

9 Williams TM, Sotgia F, Lee H, Hassan G, Di Vizio D, Bonuccelli G, Capozza F, Mercier I, Rui H, Pestell RG, Lisanti MP: Stromal and epithelial caveolin-1 both confer a protective effect against mammary hyperplasia and tumorigenesis: caveolin-1 antagonizes cyclin D1 function in mammary epithelial cells. Am J Pathol 2006;169:1784-1801.

10 Elston CW, Ellis IO: Pathological prognostic factors in breast cancer. I. The value of histological grade in breast cancer: experience from a large study with long-term follow-up. Histopathology 2002;41:154-161.

11 Mercier I, Casimiro MC, Wang C, Rosenberg AL, Quong J, Minkeu A, Allen KG, Danilo C, Sotgia F, Bonuccelli G, Jasmin JF, Xu H, Bosco E, Aronow B, Witkiewicz A, Pestell RG, Knudsen ES, Lisanti MP: Human breast cancer-associated fibroblasts (CAFs) show caveolin-1 downregulation and RB tumor suppressor functional inactivation: implications for the response to hormonal therapy. Cancer Biol Ther 2008;7:1212-1225.

12 Witkiewicz AK, Dasgupta A, Sotgia F, Mercier I, Pestell RG, Sabel M, Kleer CG, Brody JR, Lisanti MP: An absence of stromal caveolin-1 expression predicts early tumor recurrence and poor clinical outcome in human breast cancers. Am J Pathol 2009;174:2023-2034.

13 Sloan EK, Ciocca DR, Pouliot N, Natoli A, Restall C, Henderson MA, Fanelli MA, CuelloCarrion FD, Gago FE, Anderson RL: Stromal cell expression of caveolin-1 predicts outcome in breast cancer. Am J Pathol 2009;174:2035-2043.

14 Pinilla SM, Honrado E, Hardisson D, Benitez J, Palacios J: Caveolin-1 expression is associated with a basal-like phenotype in sporadic and hereditary breast cancer. Breast Cancer Res Treat 2006;99: 85-90.

15 Savage K, Lambros MB, Robertson D Jones RL, Jones C, Mackay A, James M, Hornick JL, Pereira EM, Milanezi F, Fletcher CD, Schmitt FC, Ashworth A, Reis-Filho JS: Caveolin 1 is overexpressed and amplified in a subset of basal-like and metaplastic breast carcinomas: a morphologic, ultrastructural, immunohistochemical, and in situ hybridization analysis. Clin Cancer Res 2007;13:90-101.

16 Perrone G, Altomare V, Zagami M, Morini S, Petitti T, Battista C, Muda AO, Rabitti C: Caveolin-1 expression in human breast lobular cancer progression. Mod Pathol 2009;22:71-78.

17 Witkiewicz AK, Dasgupta A, Nguyen KH, Liu C, Kovatich AJ, Schwartz GF, Pestell RG, Sotgia F, Rui H, Lisanti MP: Stromal caveolin-1 levels predict early DCIS progression to invasive breast cancer. Cancer Biol Ther 2009;8:1071-1079.

18 Chen ST, Lin SY, Yeh KT, Kuo SJ, Chan WL, Chu YP, Chang JG: Mutational, epigenetic and expressional analyses of caveolin-1 gene in breast cancers. Int J Mol Med 2004;14:577-582. 